\title{
A cadeia de suprimentos e a competitividade das empresas do arranjo produtivo local do biscoito de São Tiago-MG
}

\author{
Leandro Eduardo Vieira Barros ${ }^{1}$ \\ Antônio Cleber da Silva ${ }^{2}$ \\ Paulo Lúcio de Lacerda ${ }^{3}$ \\ Maria Clara Ferreira ${ }^{4}$
}

\begin{abstract}
Resumo
O município de São Tiago-MG, por concentrar unidades produtoras de biscoito, foi reconhecido como Arranjo Produtivo Local (APL) pela Secretaria Extraordinária de Desenvolvimento Integrado e Fóruns Regionais, do estado de Minas Gerais. Nesse contexto, o objetivo deste artigo é descrever a cadeia de suprimentos e a relação entre as empresas do arranjo produtivo local do município de São Tiago, de forma a compreender esse APL. Para tal fim, utilizou-se de um questionário para obtenção de dados primários. Para a análise dos dados quantitativos, foi utilizada estatística descritiva e estatística multivariada com aplicação da técnica de análise fatorial. Os resultados apontam que a cadeia principal de suprimentos apresenta condições adequadas para a produção de biscoito, porém a cadeia secundária apresenta limitações sobre alguns aspectos. Detectou-se que as relações entre as empresas do aglomerado são caracterizadas pela competição. Em conclusão, são apresentadas as limitações da pesquisa e sugestões para futuras pesquisas, bem como para o APL e aos órgãos governamentais.
\end{abstract}

Palavras-chave: Arranjo produtivo local. Cadeia de suprimentos. Competição. Fábricas de biscoito. São Tiago-MG.

\section{The supply chain and competitiveness between companies in the cluster of biscuit in São Tiago-MG}

\begin{abstract}
The municipality of São Tiago/MG, for concentrating biscuit producing units, has been recognized as a local productive cluster by the Extraordinary Secretariat for Integrated Development and Regional Forums, of the Minas Gerais State. In this context, the objective of this article is to describe the supply chain and relationship between companies in the cluster of the municipality of São Tiago, in order to understand that APL. For this purpose, a survey was employed to obtain primary data. For quantitative data analysis, descriptive statistics and factorial analysis technique were applied. The findings show that the main supply chain has adequate conditions for the production of biscuits, but the secondary chain has limitations in some aspects. It has been found that the relationships between the companies in the cluster are essentially characterized by competition. In conclusion, the study presents its limitations and suggestions for future research, as well as for the cluster and government agencies.
\end{abstract}

Keywords: Cluster. Supply chain. Competition. Biscuit factories. São Tiago-MG.

1 Doutor em Administração (UFLA). Professor do Instituto Federal de Educação, Ciência e Tecnologia (IFECT) do Sudeste de Minas Gerais - São João Del-Rei. Orcid: 0000-0003-1848-8844. leandro.barros@ifsudestemg.edu.br

${ }^{2}$ Mestre em Administração (FIPEL). Professor do Instituto Federal de Educação, Ciência e Tecnologia (IFECT) do Sudeste de Minas Gerais - São João Del-Rei. cleber@ifsudestemg.edu.br

${ }^{3}$ Graduando em Tecnologia em Logística no Instituto Federal de Educação, Ciência e Tecnologia (IFECT) do Sudeste de Minas Gerais - São João Del-Rei. Bolsista de Iniciação Científica. paulolacerdareal@gmail.com

${ }^{4}$ Graduanda em Tecnologia em Logística no Instituto Federal de Educação, Ciência e Tecnologia (IFECT) do Sudeste de Minas Gerais - São João Del-Rei. Bolsista de Iniciação Científica. m.claraferreira@outlook.com.br 


\section{Introdução}

Os Arranjos Produtivos Locais (APL's) podem ser considerados uma alternativa de formatos produtivos territoriais. Os APL's são aglomerações regionais e ou locais de setores especializados, cujo objetivo maior é aumentar a competitividade dos pequenos negócios, bem como contribuir para o desenvolvimento econômico local e regional. Furtado (2003) argumenta que para haver desenvolvimento tem que ocorrer desenvolvimento tecnológico. Oliveira (2002) afirma que além das questões citadas, o desenvolvimento deve ter como objetivo a melhoria da qualidade de vida das pessoas. Assim, entende-se que os APL's exercem esse papel de gerar rendas, contribuir para o desenvolvimento tecnológico e também melhorar a vida das pessoas.

Devido a importância dos APLs, em 2004, foi criado o Observatório Brasileiro de APL com a finalidade de coordenar as ações governamentais em nível federal, estadual e municipal. Sua coordenação é realizada pelo Ministério da Indústria, Comércio Exterior e Serviços, com finalidade de elaborar e propor diretrizes gerais para a atuação coordenada do governo no apoio aos APLs no território nacional.

Nesse contexto, o município de São Tiago, foi reconhecido oficialmente como APL pela Secretaria Extraordinária de Desenvolvimento Integrado e Fóruns Regionais (Seedif), em 08 de setembro de 2018, assim, o município recebeu a chancela de polo produtor de biscoitos (SÃO TIAGO, 2018). É um município localizado no Campo da Vertentes, em Minas Gerais, conhecido como a "terra do café com biscoito". O município concentra grande produção de biscoitos em diversas fábricas, abastecendo o mercado regional e também outros estados.

Em setembro de 2019, São Tiago possuía 80 micros e pequenas empresas (MPEs) no setor de Indústria de produtos alimentícios, bebidas e álcool etílico, gerando 509 empregos formais, de acordo com o Ministério do Trabalho e Emprego (MTE, 2020). Segundo o Instituto Brasileiro de Geografia e Estatística (IBGE), o município possui 326 empresas, empregando 1549 trabalhadores e população estimada de 10.561 pessoas (IBGE, 2020).

Diante da relevância desse seguimento para o município, este trabalho tem por objetivo geral descrever a cadeia de suprimentos e a relação entre as empresas do arranjo produtivo local do biscoito do Município de São Tiago-MG. Especificamente, procura-se caracterizar o APL de São Tiago; descrever a cadeia de suprimentos do biscoito e, finalmente, apresentar as relações entre as empresas do APL. Dessa forma, deseja-se responder à seguinte questão de pesquisa: como funciona a cadeia de suprimentos e a relação entre as empresas do arranjo produtivo local 
do biscoito do Município de São Tiago-MG? Para responder a essa interrogação utilizou-se de questionário para obtenção de dados primários. Para análise dos dados quantitativos, foi utilizada estatística descritiva e estatística multivariada com aplicação da técnica de análise fatorial.

Este trabalho se justifica pela importância das Micros e Pequenas Empresas (MPEs) para o desenvolvimento local e regional, em especial a representatividade do seguimento, que conta com $24,5 \%$ das empresas do município e emprega $32,8 \%$ dos trabalhadores formais (MTE, 2020). Assim, os APLs podem ser considerados uma relevante fonte de trabalho, de renda e de desenvolvimento local e regional (MAGNAVITA et al., 2011). Na perspectiva empírica, torna-se fundamental a compreensão do funcionamento da cadeia de suprimentos e das relações das empresas no APL, de forma que os resultados possam orientar e impulsionar as políticas públicas no arranjo produtivo. Do ponto de vista teórico, o estudo contribui para compreender o quanto as relações das empresas podem influenciar nos resultados do mercado e produzir novas reflexões teóricas que possibilitem um aprimoramento ao entendimento sobre os aglomerados produtivos.

Além dessa introdução, o artigo está dividido em quatro seções. Na primeira, foi feita uma revisão na literatura para estudar o que são os arranjos produtivos locais, bem como as principais relações existentes neles e também definir a cadeia de suprimentos do biscoito de São Tiago. Posteriormente, foi feito o detalhamento da metodologia da pesquisa; na terceira, a apresentação e discussão dos resultados, e por último, as considerações finais.

\section{Os Arranjos Produtivos Locais (APL)}

O termo Arranjo Produtivo Local (APL) é uma nomenclatura brasileira que dentro da administração e do setor industrial tem o mesmo sentido de "cluster" (MENDONÇA et al., 2012). Segundo Porter (1999), os clusters são concentrações de empresas e instituições numa mesma região, onde existe a comunicação entre essas empresas e a troca de informações, como por exemplo o relacionamento em comum com clientes e fornecedores e o desenvolvimento de novas tecnologias. Ou seja, o termo é atribuído a aglomerações de empresas produtivas de um mesmo setor econômico que se comunicam por possuírem características semelhantes e coabitarem na mesma região. Segundo Mytelka e Farinelli (2005), os APLs podem ser 
aglomerações espontâneas de empresas de um determinado setor ou aglomerações motivadas pelas políticas públicas como parques tecnológicos, incubadoras e zonas francas.

Justen e Souza (2017), entendem que os APLs são aglomerações territoriais de agentes econômicos, políticos e sociais, com foco em um conjunto específico de atividades econômicas. Para Sampaio, Marini e Santos (2018), essas aglomerações produtivas possibilitam uma vantagem competitiva para as empresas que estão dentro do APL em relação as demais.

Amaral (2013) esclarece que o APL deve possuir espaço geográfico definido onde estão presentes os atores sociais, os agentes, as instituições e as empresas que de alguma forma estão interligadas entre si e com outras instituições. Esses APLs podem ser rudimentares, complexos e articulados. Segundo o Sebrae (2003), o APL deve possuir uma aglomeração de empresas com um ramo de atividade produtora principal. Outros fatores relevantes são: número de empregos diretos e indiretos gerados, faturamento, mercado e possibilidade dos empreendedores informais se organizarem para se tornarem empreendedores formais.

Podem ser observadas diversas vantagens para as empresas que fazem parte de um APL, como avanços tecnológicos, qualificação de mão de obra, troca de informações, desenvolvimento da cadeia de suprimentos, marketing e o acesso a novos mercados. Os arranjos também aceleram a inovação e fomentam empresas, facilitando a coordenação e o aperfeiçoamento mútuo em áreas afins, preservando a competição e a rivalidade. Gera-se um ambiente de comunicação entre empresas e fornecedores, governo e instituições (PORTER, 1999; SCHMITZ e NADVI, 1999, BRASIL, 2011).

Machado, Costa e Pólvora (2018) acrescentam que os APLs possibilitam uma diferenciação empresarial proporcionando benefícios mútuos para as empresas inseridas, como: vantagens competitivas; inovações empresariais; interação e os aspectos de alavancagem empresarial por meio da cooperação entre os atores; e fortalecimento das atividades das empresas no mercado. A procura de qualidade e preço justo, em uma determinada região geográfica reduzindo o tempo de busca pelo produto ou serviço, também são vantagens facilitadoras que atraem clientes aos locais reconhecidos como polos produtores (PORTER, 1999, TAKEDA et al., 2008, RODRIGUEZ, 2014).

Os APLs desempenham um importante papel para as MPEs, possibilitando o aumento de capacidade produtiva e oportunidades de sobrevivência no mercado competitivo. Além disso, essas empresas contribuem para o desenvolvimento local e regional (VIEIRA, 2011, MARINI e SILVA, 2014), para a economia, na geração de emprego e renda (IPIRANGA, AMORIM e FARIA, 
2007). Neste contexto, Mytelka e Farinelli (2005) desenvolveram uma tipologia que distinguem os APLs em relação a capacidade de realizar mudanças e inovação. Os APLs podem ser caracterizados como informal, organizado e inovador.

Os aglomerados informais são formados por MPEs com baixa capacidade gerencial e tecnológica, possuem mão de obra de baixa qualidade, infraestrutura inadequada, ausência de apoio financeiro e poucas inovações. As relações são fracas, com pouca confiança, muita competição e baixo compartilhamento de informações. Os aglomerados informais são prevalecentes em países em desenvolvimento como o Brasil, e o papel do Estado, através de políticas públicas que visem o fornecimento de serviços tecnológicos, treinamento e crédito, tem mostrado ser de fundamental importância para o crescimento desses aglomerados.

Os aglomerados organizados são formados por empresas de pequeno e médio porte, com níveis de competências maiores. É constituído pela cooperação e pelo trabalho em rede pelas empresas participantes. Detém flexibilidade e resposta rápida ao mercado, possuem capacidade para adaptar a novas tecnologias e desenvolver novos produtos e processos. Essa condição proporciona maior competitividade. Esses aglomerados não estão organizados suficientemente para apoiar um processo de melhoria contínua, o que limita a geração de inovações significativas. Nos aglomerados organizados, a competição, como nos informais, também é elevada. A cooperação, embora se apresente com maior intensidade, ainda não é sustentada. Países em desenvolvimento, como o Brasil, possuem esse tipo de aglomerado.

Os aglomerados inovadores são constituídos por pequenas, médias e grandes empresas, e caracterizam-se por demonstrar alta capacidade de criação e um processo contínuo de inovação ao longo do tempo. A confiança, cooperação e capacidade de inovação se apresentam em elevado grau. A mão de obra é qualificada e a infraestrutura é adequada. Os aglomerados inovadores têm forte presença no mercado internacional, com elevados índices de exportação. A presença do Estado e do governo local têm sido de grande importância para o desenvolvimento e coordenação desses aglomerados. Os países desenvolvidos, em geral, apresentam experiências com aglomerados inovadores.

Dentro dos APLs acontecem três tipos de relações interorganizacionais, a competição, a cooperação e a coopetição que é a junção das duas relações anteriores (LACOSTE, 2012). A cooperação é a forma esperada de interação dentro de um APL, na tentativa de aumentar a competitividade das empresas do APL contra empresas fora do aglomerado. A cooperação pode ser abordada como um processo social, que busca em ação conjunta, um objetivo ou finalidade 
em comum. A cooperação pode ser entendida como uma ação conjunta, um objetivo ou finalidade em comum das empresas. Para Pesämaa e Hair (2008) a cooperação é concebida como uma prática adotada por organizações interessadas no desenvolvimento de interesses coletivos.

A partir da tipologia sobre APLs desenvolvida por Mytelka e Farinelli (2005), foi construída a figura 1, que pode ser observada a seguir. Para compreender a figura, mais próximo ao centro são situações ou relações baixas, poucas ou nenhumas e na extremidade do centro as relações entre as empresas são elevadas ou altas.

Figura 1 - Tipologia sobre APLS

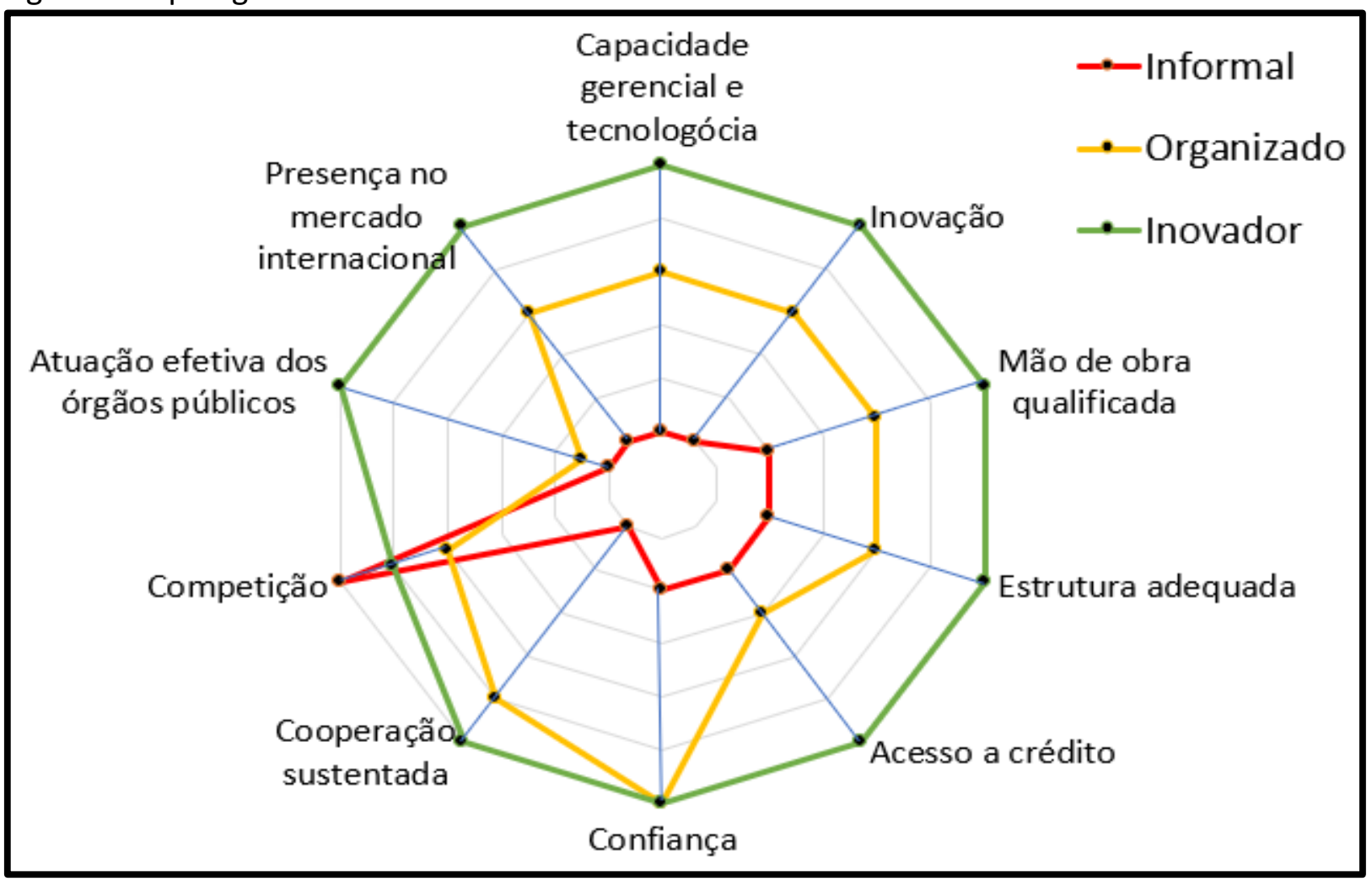

Fonte: Desenvolvida pelos autores a partir da tipologia de Mytelka e Farinelli (2005).

Ao mesmo tempo, é reconhecido que as experiências e as competências das pessoas responsáveis pela gestão dessas organizações são fundamentais para a construção de consensos e do comprometimento com os objetivos coletivo. No entanto, não é possível desconsiderar a existência das relações de competição dentro do próprio arranjo produtivo, posto que as relações entre os membros também são marcadas pela busca de ampliação de mercado, ponto de partida à prática competitiva (PORTER, 1999).

As empresas buscam desenvolver forças competitivas e usá-las a seu favor, desenvolvendo uma estratégia para alcançar uma posição relativa no mercado. De acordo com Pietro, Laurindo e Carvalho (2007), o desenvolvimento da competição deve definir em caráter 
amplo a forma como a empresa irá agir, quais devem ser suas metas e quais as políticas necessárias para que essas metas sejam atingidas. Segundo Amaral (2013), a competição existe entre as empresas na busca de objetivos comuns ou concorrenciais que impulsionam a concorrência e a produtividade das empresas presentes no APL.

A competitividade é a busca pela alteração da posição da empresa no seu setor de atuação em relação aos concorrentes, e sua formulação deve considerar todos os agentes com os quais a empresa compete (PORTER, 1998). Na ótica de Porter (1999), a competitividade de um país está relacionada à sua capacidade de inovar e melhorar. Desta forma, as empresas se beneficiam de rivais internos fortes, de uma base de fornecedores agressivos e de clientes locais exigentes, ou seja, a importância de existir a competitividade. Mas existe a necessidade de cada país oferecer condições para competitividade, tais como incentivar o desempenho competitivo, políticas governamentais de longo prazo. No entanto, nenhum país ou empresa tem condições de competir em todos os setores.

Para que empresas ou países sejam competitivos é necessário antecipar as mudanças do mercado, e manter a vantagem competitiva de forma contínua. Desta forma, o "diamante" da vantagem nacional estabelece atributos que opera para os setores econômicos de forma isolada ou em sistema, que são:

1. Condições dos fatores. São os fatores de produção, como mão de obra qualificada e infraestrutura.

2. Condições de demanda. São as características da demanda no mercado interno para serviços e produtos.

3. Setores correlatos e de apoio. A presença ou ausência de fornecedores que sejam competitivos.

4. Estratégia, estrutura e rivalidade das empresas - são condições predominantes no país, que determinam como as empresas são constituídas, organizadas e gerenciadas, assim como a natureza da rivalidade no mercado interno (PORTER, 1999).

Diversos fatores podem contribuir para o crescimento da competição entre as empresas que compõem um APL, como a informalidade e a baixa resistência de entrada, dependendo do setor. Esses fatores têm como consequência principal o aumento da concorrência entre essas empresas (PORTER, 1999).

Como se constata, as baixas barreiras de entrada são apontadas como um fator que pode aumentar a competição dentro de um APL. Para Vieira et al., (2016), barreira à entrada é uma 
teoria econômica que visa analisar os desafios e dificuldades encontradas por novas empresas no mercado em seu processo de inserção. As barreiras à entrada podem influenciar no número de empresas ativas, na estrutura de mercado, na produção agregada e no preço praticado. Segundo Florian e Lorenzo (2008), dois fatores que diminuem barreiras à entrada em determinados setores são a necessidade de um baixo investimento inicial para iniciar uma produção e a exigência de pouca capacitação de gestores e mão de obra. As baixas barreiras de entrada também facilitam o aparecimento de produtores informais, que além das questões anteriormente citadas, ainda não lidam com a fiscalização e as tributações da maneira correta.

A informalidade das organizações é um fator prejudicial aos participantes formais do APL, pois geram trabalhos informais, seus produtos e serviços não tem sua qualidade atestada por órgão competentes e não recolhem tributos ao fisco. Destaca-se que o crescimento da informalidade ocorre em períodos de crise, devido à postura defensiva de individualismo adotada pelas empresas, normalmente levando ao aumento significativo da competitividade desleal e diminuição da cooperação. Por outro lado, empresas maiores que gerenciam seus processos e qualidade formalmente possuem mais acessos a mercados de maior importância, enquanto as informais ficam mais restringidas às vendas locais (FLORIAN e LORENZO, 2008).

Outra relação entre organizações presente no APL é a relação de coopetição, que é uma estratégia de negócios baseada em competir e cooperar ao mesmo tempo. Ela vem sendo muito observada em empresas inseridas em redes e pode trazer diversos ganhos para as organizações (CZERNEK e CZAKON, 2016). Esses autores observaram a redução de custos, o acesso e compartilhamento de informações e recursos, a geração de valor agregado para clientes e a busca pela inovação, como os ganhos potenciais resultantes dessa estratégia.

Segundo Nalebuff e Brandenburger (1996), as empresas devem manter uma visão mais ampla sobre cooperação e competição de forma a criar e capturar as duas dimensões ao mesmo tempo, proporcionando uma maior dinâmica no seu relacionamento. Assim, cooperação e competição ocorrem de forma concomitante, permitindo assegurar poder de barganha, eficiência e diferencial de mercado e a responder as necessidades e demandas do mercado interno e externo. 


\subsection{A Cadeia de Suprimentos do APL}

A gestão da cadeia de suprimentos (Supply Chain Management - SCM) tem emergido como modelo competitivo estratégico e gerencial para empresas. É o sistema que as organizações entregam produtos e serviços a seus consumidores, em uma rede de organizações interligadas. A SCM vai além da gestão interna, ela abrange também os parceiros comerciais de empresas focais ou centrais (empresas que exercem a governança da cadeia) visando sua integração, a constituição de parcerias e a co-produção (HANSEN e OLIVEIRA, 2009).

Para Leite (2017), a SCM é um processo estratégico que atua na previsão da demanda, na seleção dos fornecedores, no fluxo de materiais, nos contratos com os stakeholders, no estudo das informações, nas movimentações financeiras, na expansão de novas instalações como fábricas, armazéns, centros de distribuição. Cuida também do relacionamento com clientes, além de abranger questões mais amplas como a economia, a sociedade, o meio ambiente.

Stakeholderes são pessoas, grupos ou organização que podem impactar ou sofrer impacto da decisão desses atores, ou seja, irão influenciar nas empresas que estão atuando no APL, no caso desta pesquisa: órgão governamentais, instituições públicas, vigilância sanitária, sindicatos e associação (PMI, 2017).

Segundo Hansen e Oliveira (2009), a avaliação crítica da cadeia de suprimentos dos arranjos produtivos locais, permite bons resultados por racionalizar as atividades das empresas pertencentes ao aglomerado, com a medição de desempenho. Lucca e Trennhohl (2016) acrescentam a cadeia de suprimentos estruturada no APL possibilita maior competitividade as empresas e aumento da renda do produtor.

Para Masquietto, Sacomano Neto e Guiliani (2010), o gerenciamento do APL deve ter como objetivo agregar valor à cadeia e gerar garantia de vantagem competitiva sustentável, pela gestão permanente do negócio, da cadeia de suprimentos e do território.

É difícil as empresas possuírem todas as competências necessárias para o fornecimento do produto ao cliente final, sendo natural que as empresas inseridas em arranjos produtivos locais participem de uma ou mais cadeias de suprimentos. Portanto, as organizações realizam apenas uma fração das operações necessárias e passam a depender também do desempenho de outras empresas que fazem parte da supply chain (MACADAR, 2007).

Nesse contexto, as operações realizadas no APL ocorrem dentro da cadeia produtiva. A cadeia produtiva é caracterizada por todas os estágios, envolvidos direta ou indiretamente, no 
atendimento de um cliente. A cadeia de suprimentos envolve fabricantes, fornecedores, transportadoras, depósitos, varejistas e os clientes (CHOPRA e MEINDL, 2003). Assim, a cadeia de suprimentos inicia na aquisição, passa pela transformação e termina na distribuição do produto ao cliente. Na Figura 2 apresenta uma síntese do modelo teórico que fundamenta esta pesquisa.

Figura 2. Modelo teórico do APL de São Tiago-MG

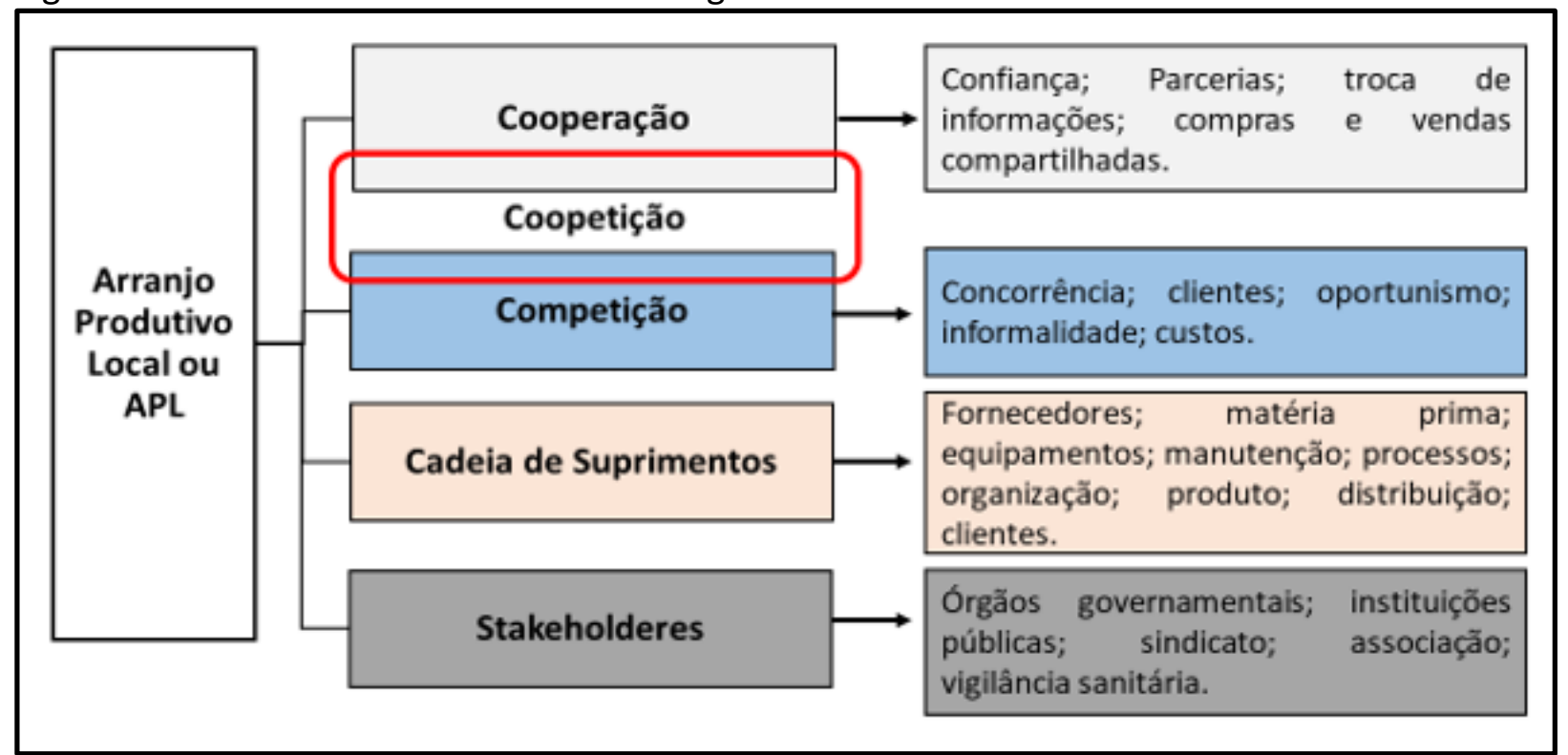

Fonte: Elaborado pelos autores.

A figura 2 apresenta as interações que ocorrem em um APL a partir da literatura. Existe a relação entre as empresas que caracteriza cooperação, competição ou coopetição que é junção das duas interações anteriores. Há no APL em estudo a cadeia produtiva do biscoito, que envolve desde os fornecedores, passando pelos fabricantes, distribuidores e varejistas até o consumidor final. E por fim, os stakeholders que se relacionam no APL: os órgãos governamentais, instituições públicas, sindicato, associação e vigilância sanitária.

\section{Metodologia}

A presente pesquisa refere-se a um survey para descrever as características, os relacionamentos, os comportamentos e os fatos vigentes no aglomerado produtivo do Biscoito, no município de São Tiago-MG (COLLIS; HUSSEY, 2005). Sua abordagem é quantitativa, pois busca representar a realidade por mensurações objetivas de uma amostra (HAIR et al., 2005). A unidade de análise será o aglomerado produtivo de São Tiago/MG. 
Os dados coletados são primários e secundários. Os dados secundários foram obtidos nas bases de dados do Ministério do Trabalho e Emprego (MTE) e do Instituto Brasileiro de Geografia e Estatística (IBGE). Para coleta de dados primários foi elaborado um questionário com perguntas objetivas sobre a caracterização da empresa, a estrutura da cadeia de suprimentos, as relações das empresas, confiança entre os atores, dificuldades enfrentas pelas empresas e a atuação dos órgãos públicos no APL.

No momento da coleta havia 40 empresas registras no Ministério do Trabalho e Emprego (MTE, 2019). No município existe a Associação São-Tiaguense do Biscoito (Assabiscoito), porém 20 empresas fazem parte da associação. A coleta ocorreu nos meses de agosto e setembro de 2019, com 36 empresas. Todas empresas foram visitadas, porém houve recusas em responder o questionário por parte de algumas. Os sujeitos da pesquisa foram os gerentes ou proprietários das empresas sendo escolhidos por critério de acessibilidade (HAIR et al., 2009). Ressalta-se que os respondentes assinaram o Termo de Consentimento e Livre Esclarecido. O projeto da pesquisa foi aprovado pelo Comitê de Ética e Pesquisa, conforme protocolo CAAE 12591019.7.0000.5588.

Para análise dos dados quantitativos, foi utilizada estatística descritiva em uma planilha eletrônica e estatística multivariada com aplicação da técnica de análise fatorial por meio de pacote estatístico específico. A análise fatorial é uma técnica exploratória de dados que usa as correlações observadas entre as variáveis para estimar o(s) fator(es) comum(ns) e as relações entre variáveis (MARÔCO, 2010). Os fatores procuram sintetizar o conteúdo informacional essencial proveniente das variáveis originais, traduzidas em poucos fatores.

$\mathrm{O}$ teste de esfericidade de Bartlett e o de Kaise-Meyer-Olkin (KMO) foram aplicados a fim de averiguar se a análise fatorial seria um modelo apropriado aos dados. Os resultados desses testes apontam se os dados são ou não adequados para aplicação da análise fatorial. A técnica de rotação Varimax forneceu o modelo mais ajustado. Em seguida, buscou-se a caracterização dos fatores, para avaliar a correspondência do fator com os itens (HAIR et al., 2009).

Os dados primários foram tabulados com o auxílio do software Microsoft Excel ${ }^{\oplus}$ e, depois, realizadas as análises uni e multivariada por meio do software Statistical Package for the Social Science ${ }^{\circledast}$ (SPSS), versão 18. 


\section{Apresentação e análise dos resultados}

O aglomerado produtivo de São Tiago/MG é formado por MPEs, do setor alimentício, na produção de biscoito de polvilho ou "torradinha", rosquinhas e similares. Trata-se de um APL de aglomerações de empresas de forma espontânea (MYTELKA e FARINELLI, 2005). A Tabela 1 apresenta o perfil das empresas pesquisadas.

Tabela 1. Perfil das empresas pesquisas do APL de São Tiago/MG

\begin{tabular}{|c|c|c|c|}
\hline Dados & Categorias & Número de empresas & $\%$ \\
\hline \multirow[t]{3}{*}{ Fundação no período } & 1990-1999 & 09 & 25,0 \\
\hline & 2000-2009 & 14 & 38,9 \\
\hline & 2010-2019 & 13 & 36,1 \\
\hline \multirow[t]{2}{*}{ Origem do negócio } & Familiar & 22 & 61,1 \\
\hline & Não familiar & 14 & 38,9 \\
\hline \multirow[t]{5}{*}{ Número de empregados } & $1-10$ & 14 & 38,9 \\
\hline & $11-20$ & 11 & 30,6 \\
\hline & $21-30$ & 6 & 16,6 \\
\hline & $31-40$ & 4 & 11,1 \\
\hline & $41-50$ & 1 & 2,8 \\
\hline \multirow[t]{7}{*}{ Produção mensal em quilos } & Até de 5.000 & 16 & 44,4 \\
\hline & $5001-10.000$ & 5 & 13,9 \\
\hline & $10.000-15.000$ & 3 & 8,3 \\
\hline & $15.001-20.000$ & 4 & 11,1 \\
\hline & $30.001-40.000$ & 2 & 5,6 \\
\hline & $50.001-100.000$ & 4 & 11,1 \\
\hline & Não respondeu & 2 & 5,6 \\
\hline \multirow[t]{3}{*}{ Vendas } & Balcão & 14 & 38,9 \\
\hline & Consumidor final & 21 & 58,3 \\
\hline & Misto & 1 & 2,8 \\
\hline \multirow[t]{3}{*}{ Distribuição dos produtos } & Frota própria & 6 & 16,7 \\
\hline & Terceirizada & 22 & 61,1 \\
\hline & Mista & 8 & 22,2 \\
\hline \multirow[t]{2}{*}{ Controle de estoque } & Sim & 26 & 72,2 \\
\hline & Não & 10 & 27.8 \\
\hline \multirow[t]{3}{*}{ Formas de controle de estoque } & Software & 3 & 11,5 \\
\hline & Planilha eletrônica & 11 & 42,3 \\
\hline & Caderno & 12 & 46,2 \\
\hline \multirow[t]{9}{*}{ Faturamento mensal } & $0-\mathrm{R} \$ 10.000,00$ & 3 & 8,3 \\
\hline & $\mathrm{R} \$ 10.001,00-\mathrm{R} \$ 20.000,00$ & 5 & 13,9 \\
\hline & $\mathrm{R} \$ 20.001 .00-\mathrm{R} \$ 30.000,00$ & 3 & 8,3 \\
\hline & $\mathrm{R} \$ 30.001,00-\mathrm{R} \$ 40.000,00$ & 4 & 11,1 \\
\hline & $\mathrm{R} \$ 40.001,00-\mathrm{R} \$ 50.000,00$ & 3 & 8,3 \\
\hline & $\mathrm{R} \$ 50.001,00-\mathrm{R} \$ 60.000,00$ & 4 & 11,1 \\
\hline & $\mathrm{R} \$ 60.001,00-\mathrm{R} \$ 70.000,00$ & 2 & 5,6 \\
\hline & Acima $100.000,00$ & 9 & 25,0 \\
\hline & Não respondeu & 3 & 8,3 \\
\hline
\end{tabular}

Fonte: Dados da pesquisa (2019). 
Observa-se que 63,9\% das empresas possuem mais de 10 anos de fundação, $61 \%$ são de origem familiar e 69,5\% tem até 20 funcionários, com média de 17 funcionários. A produção de $44,4 \%$ das fabricas é de até 5.000 quilogramas, das quais $58,3 \%$ são vendidas para o consumidor final. Para $94,4 \%$ dos produtores, os produtos fabricados são de qualidade. O destino da produção é diversificado, com predominância na região do Campo das Vertentes, Belo Horizonte, Rio de Janeiro e São Paulo. O transporte é realizado em 61,1\% dos casos com frota terceirizada. O controle de estoque é realizado por $72,2 \%$ das fábricas, por meio de anotações manuscritas em caderno em $46,2 \%$, seguido de planilha eletrônica em $42,3 \%$ das empresas. O faturamento bruto é diversificado, porém com destaque de $25 \%$ para superior a $\mathrm{R} \$ 100.000,00$ por mês.

Assim, pode-se inferir que o APL é composto de MPEs, de origem familiar, com a gestão das informações do negócio de forma incipiente. No estudo de Resende et al., (2012) sobre a proposição de um sistema de medição de desempenho para as fábricas de biscoitos de São Tiago, os achados demonstram que a justificativa para o ingresso na fabricação de biscoitos é a tradição familiar e a influência cultural da cidade nesse seguimento. Em relação a gestão do negócio, processo de fabricação e controle do estoque são realizados de forma incipiente, semelhante aos resultados encontrados por Resende et al., (2012). Segundo o Manual de Atuação em Arranjos Produtivos Locais - APLs (BRASIL, 2011) as instituições públicas devem desenvolver a capacitação nas MPEs com temáticas voltadas ao processo produtivo, gestão de estoque, cadeia de suprimentos, à gestão financeira, vendas e atividades de acesso a novos mercados.

As empresas que não realizam controle de estoque se caracterizam com fundação nos últimos 8 anos, baixo número de funcionários, baixa produção e baixo rendimento bruto, em comparação com as demais empresas do APL. Assim, pode-se inferir que são empresas que estão iniciando suas atividades e empregam poucas técnicas de gestão.

Em relação à análise fatorial, foram satisfatórios os resultados do teste $\operatorname{KMO}(0,630)$ que analisou a correlação simples entre as variáveis e o teste de Esfericidade de Bartlett (significativo com $p$-value $=0,003)$. Conforme parâmetros apontados por Hair et al. (2009) e Marôco (2010) ambos os resultados atestam o bom ajuste da análise fatorial. Verificou-se haver correlação entre as variáveis de cada fator, com valores superiores a 0,387. Quando essa correlação ultrapassa 0,30, há evidência suficiente de que a técnica de fatorial é adequada e as análises apresentam validade estatística (HAIR et al.,2009). A análise fatorial gerou 4 fatores e sua variância total explicada foi de $68,8 \%$. A matriz dos componentes rotacionada pode ser observada na Tabela 2 . 
Tabela 2. Matriz rotacionada e fatores extraídos pela análise fatorial

\begin{tabular}{|c|c|c|c|c|}
\hline \multirow[b]{2}{*}{ Variáveis } & \multicolumn{4}{|c|}{ Fator } \\
\hline & 1 & 2 & 3 & 4 \\
\hline Distribuição e entrega de produtos & 0,852 & & & \\
\hline Intermediários & 0,729 & & & \\
\hline Localização da empresa & 0,609 & & & \\
\hline Em época de crises a cooperação aumenta & $-0,506$ & & & \\
\hline Há oportunismos & & 0,860 & & \\
\hline Concorrência & & 0,846 & & \\
\hline Disponibilidade de matéria prima & & & 0,887 & \\
\hline Ausência de mão de obra & & & 0,677 & \\
\hline A região facilita a cooperação & & & & $-0,894$ \\
\hline Recebimento de matéria prima & & & & 0,592 \\
\hline
\end{tabular}

Fonte: Dados da pesquisa, 2019.

A seguir tem-se a apresentação da análise e discussão dos quatro fatores extraídos da matriz de componentes rotativa. O título para cada fator foi em conformidade com os comportamentos realizados pelos atores sociais no aglomerado produtivo.

O fator 1 foi denominado de "a infraestrutura da cadeia suprimentos do APL do biscoito". Com relação às questões que compõem o fator $1,72,2 \%$ (26) dos respondentes afirmaram que o processo de distribuição e entrega de mercadorias não apresenta limitação à expansão do APL. Em relação aos intermediários logísticos, 69,4\% (25) das empresas acreditam que eles facilitam as operações de transferência de matéria-prima e do produto acabado até o consumidor final. Quanto à localização da empresa, 83,3\% (30) responderam que contribui para atração de clientes. Outras etapas da cadeia de suprimentos tiveram repostas positivas dos entrevistados em relação a fornecedores de matéria-prima, equipamentos e sua manutenção, escala de produção, embalagens e rótulos.

As evidências fornecidas pelo fator 1 permitem inferir que a infraestrutura da cadeia de suprimentos do APL é adequada e contribui para a fabricação do biscoito e destruição ao consumidor final. Os resultados específicos desse fator corroboram estudos anteriores. Em relação à matéria-prima, Resende et al., (2012) verificou que era de qualidade e não faltava no APL. Segundo Hansen e Oliveira (2009), Lucca e Trennepohl (2016) e Masquieto Neto e Guiliani (2019) essas características da cadeia de suprimentos que o APL apresenta oferece condições das empresas de criar valor, melhorar a competitividade e a facilita a gestão, proporcionando melhores resultados e desempenho organizacional. 
Já o fator 2 trata da concorrência e presença de oportunismo. As relações entre as empresas do APL se caracterizam como de competição. Desta forma, 36,6\% (13) discorda plenamente e $22,2 \%$ (8) discordam parcialmente que em época de crise a cooperação aumenta. Detectou-se que em períodos de crise a competição aumenta, sendo confirmada por 58,3\% (21) que concorda plenamente e 13,8\% (5) concorda parcialmente. A concorrência foi verificada como grande barreira enfrentada pelas empresas em 83,3\% (30) dos respondentes. Quando foi perguntado sobre a presença de oportunismo "trapaças" entre as empresas do APL pesquisado, $41,6 \%$ (15) respondentes afirmaram concordar em parte e $36,1 \%$ (13) declararam concordar plenamente. Desta forma, verifica-se que as relações entre as empresas desse APL são de competição e comportamento oportunista. Conforme Barney e Hesterly (2004), no comportamento oportunista os atores econômicos estão em busca do interesse próprio, o que não possibilita a cooperação entre as empresas devido à falta de confiança.

Na literatura, atores como Britto (2002), Barney e Hesterly (2004), Balestrin el at., (2010) apresentam os diversos benefícios para a cooperação entre as empresas. No entanto, as empresas do APL estudado não percebem esses benefícios, e assim, o comportamento predominante do APL de São Tiago é de competição. Segundo o Manual de Atuação em APLs é um desafio a mudança de paradigma das empresas em realizarem ações e objetivos comuns dentro do APL, que poderiam possibilitar a confiança, a cooperação e a governança entre as empresas do APL (BRASIL, 2011). Por outro lado, Kwasnicka e Zaccarelli (2007) e Corrêa e Gastaldon (2009) evidenciam que a competição entre as empresas do APL é necessária para sobrevivência no mercado.

Corrêa e Gastaldon (2009, p. 85) ressaltam que "a concentração geográfica das empresas e demais condições locais geram competitividade e vantagens competitivas sobre as empresas concorrentes isoladas". Assim, percebe-se um benefício da competição entre as empresas do APL em questão. A forte concorrência entre as empresas do APL já foi verificada no estudo de Resende et al., (2012) e permanece segundo os resultados deste estudo.

O fator 3 refere-se à disponibilidade de mão de obra e matéria-prima. Dos respondentes, 61,1\% (22) afirmaram que a disponibilidade de matéria prima no APL é um fator que possibilita a expansão da empresa. Em relação à disponibilidade de mão de obra, 55,5\% (20) pesquisados afirmaram que no APL não existem problemas em relação à ausência de mão de obra, já outros $22,2 \%$ (8) responderam que é uma limitação média que o APL enfrenta. Apesar da mão de obra não ser considerado um problema no $\mathrm{APL}$, foi possível identificar que o profissional com maior 
dificuldade de contratação é o forneiro. Quando existe a necessidade de formação da mão de obra, em $80,5 \%$ dos casos a formação é feita na própria empresa por meio de treinamento ou o treinamento é feito pela transmissão de conhecimento de funcionários mais experientes ou dos proprietários aos funcionários recém contratos. Esses resultados são semelhantes aos encontrados por Resende et al., (2012). O processo de treinamento é realizado dessa forma, pois não é uma mão de obra que exige muita capacitação para desenvolver seu trabalho, conforme destacado por Florian e Lorenzo (2008).

O fator 4 evidencia que a região não facilita a cooperação, mas o processo de recebimento de matéria prima é adequado para as empresas. Foi verificado que a região não facilita a cooperação entre as empresas, pelo contrário, apenas 2,7\% (01) respondeu que a relação entre as empresas é de cooperação. Sobre o processo de recebimento de matéria-prima, $88,8 \%$ (32) das empresas responderam que não enfrentam nenhum tipo de dificuldade. Assim, o fator 4 reforça as discussões anteriores que o APL apresenta uma cadeia de suprimentos adequada, mas as relações entre as empresas são de competição.

As empresas do APL percebem as dificuldades enfrentadas, bem como os benefícios de pertencer a uma concentração geográfica produtora de biscoito. As dificuldades apresentadas pelas empresas do APL são em 83,3\% dos casos referentes à concorrência entre empresas, em $86,1 \%$ à falta de incentivos governamentais e $94,4 \%$ às tarifas e impostos. Em relação à concorrência, uma situação recorrente foi a dificuldade de a empresa regularizada perante o fisco competir com empresas que são consideradas "fundo de quintal". Ou seja, empresas informais que não possuem regularização e não estão sujeitas ao regime de tributação e atendimento às normas existentes. Resultados semelhantes aos apresentados foram encontrados por Resende et al., (2012). Segundo Florian e Lorenzo (2008) é um tipo de competição desleal, pois as empresas não competem sobre o mesmo sistema de regras.

Os respondentes afirmaram que o fato de a empresa estar inserida em uma região conhecida como produtora de biscoito possibilita diversas vantagens, como: 100\% apontam o reconhecimento como polo produtor, $97,2 \%$ atração de clientes, $94,4 \%$ acesso facilitado a fornecedores, $83,3 \%$ qualidade da mão de obra, $77,7 \%$ troca de informações entre os atores, e $53,6 \%$ acesso a crédito ou financiamento. Segundo Corrêa e Gastaldon (2009), o sentimento de pertencer ao APL passa a ser um ativo da localidade, com status de produtor dentro e fora do $A P L$, o que significa que a formação é maior do que atuação individual da empresa, caracterizando o aspecto da sinergia que é obtido dessa formação. 
Porém, das empresas estudadas, $80 \%$ não consideram vantagens as compras compartilhas e $69,4 \%$ para vendas compartilhadas. Denota-se que as empresas aproveitam os benefícios advindos do APL em ações individualizadas, entretanto, quando se trata de ações coletivas não atuam de forma cooperada entre si, reforçando o comportamento competitivo. Segundo Brasil (2011), é necessário trabalhar a confiança entre as empresas por meio da oportunidade de ganhos e minimização de perdas, pois as empresas mudam de estratégia em função dos ganhos associados pela ação da cooperação.

A atuação do governo municipal foi considerada incipiente para $69,4 \%$ dos respondentes. Já as instituições públicas não proporcionam ao APL treinamento e capacitação em $50 \%$ dos casos e infraestrutura em 38.8\%. A vigilância sanitária foi considerada um órgão atuante para 69,4\% dos respondentes e a associação do biscoito em $61,1 \%$. Em questão de aprender algo novo sobre o ramo de atividade ou inovação, não foi possível identificar um meio predominante, sendo presentes diferentes ações realizadas pelas empresas, a saber: internet, fornecedores, cursos, outras empresas, Sebrae, universidade, nutricionistas e na própria empresa.

A cadeia de suprimentos principal do APL pode ser dividida em quatro etapas do processo produtivo: a primeira é a etapa de insumos que inclui matéria-prima, equipamentos e mão de obra; a etapa seguinte é o processo de fabricação dos biscoitos, ou seja, a transformação da matéria-prima em produto acabado; a terceira etapa é o processo de distribuição para o atacado, varejo, feiras livres e vendedores ambulantes, que é realizado em sua maioria por terceiros. Destaque-se que os intermediários estão entre a produção acabada e o consumidor e são vistos como facilitadores da cadeia produtiva. E por fim, o consumo no cliente final.

A cadeia de suprimentos auxiliar pode ser considera como suporte para cadeia principal. Apresenta uma atuação positiva para acesso a crédito ou financiamento, embalagens e rótulos dos produtos. A vigilância sanitária exerce uma atuação ativa no processo produtivo, contribuindo para fiscalização da qualidade do processo produtivo e a Assabiscoito tem um papel de promoção do APL, contribuindo para toda a cadeia independente de ser associado ou não. As empresas enfrentam dificuldades com a falta de incentivos governamentais, quanto a infraestrutura, treinamento e capacitação e as elevadas taxas e impostos.

Conforme destacado por Corrêa e Gastaldon (2009), o APL de São Tiago possui características que proporcionam capacidade de competição do APL como: mão de obra, infraestrutura da cadeia produtiva, tradição no setor e reconhecimento como polo produtor, o que torna possível a atração de clientes. Nesse contexto, o APL do biscoito de São Tiago dispõe 
de três fatores para seu desenvolvimento, conforme delineado por Santos (2005): 1) forte competição entre as empresas locais, 2) o ambiente geral da localidade favorável à constituição de novas empresas, e 3) a eficácia de mecanismos formais e informais para o desenvolvimento dos participantes.

Ao associar os resultados das características presentes do APL aos quatro atributos de Porter (1999), pode-se inferir que as condições de fatores e setores correlatos e de apoio de uma forma geral são eficientes e nesse trabalho trata-se da cadeia de suprimentos do biscoito, desde o fornecedor de matéria-prima, produção, distribuição (própria ou por intermediário) e consumidor final. Em relação às condições de demanda, as empresas destacaram a qualidade de produtos fabricados. E por fim, a rivalidade entre as empresas do APL que possibilita a busca pela sobrevivência no mercado e antecipar as mudanças.

A partir dos resultados da pesquisa, a Figura 3 apresenta o modelo empírico do atual estágio do APL do biscoito de São Tiago/MG:

Figura 3. Modelo empírico do APL do biscoito de São Tiago/MG

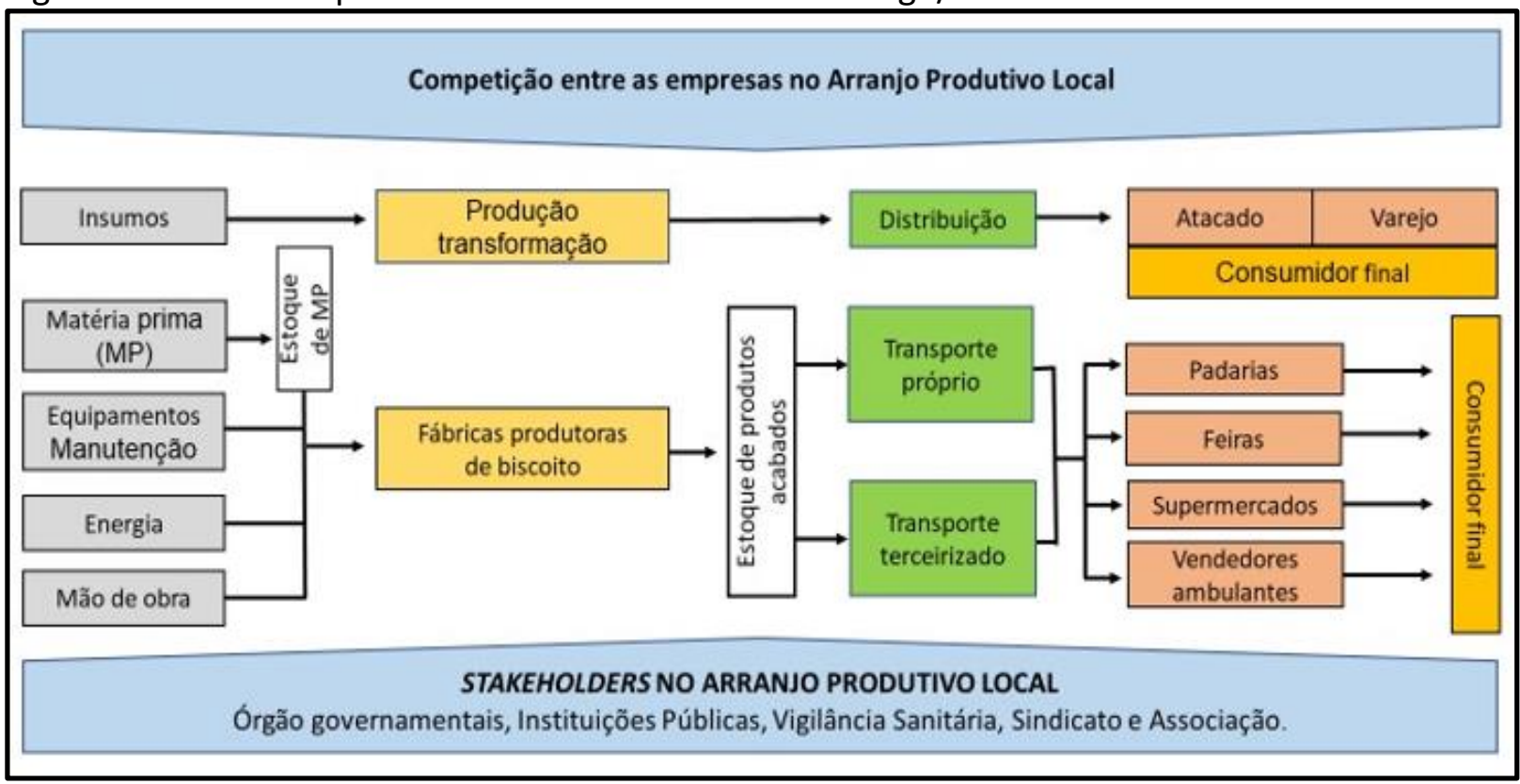

Fonte: Elaborado pelos autores, a partir dos resultados da pesquisa.

A Figura 3 busca representar o APL em estudo e seus atores sociais. No centro é apresentada a cadeia de suprimentos desde os insumos até o consumidor final. Na parte superior apresenta a relação entre as empresas dentro do APL, que é de competição em todos os estágios da cadeia produtiva. Na parte inferior, os stakeholders que atuam ou deveriam atuar dentro do APL. 


\section{Considerações finais}

O objetivo nesta pesquisa foi descrever a cadeia de suprimentos e a relação entre as empresas do arranjo produtivo local do biscoito do Município de São Tiago-MG. Conclui-se que a cadeia de suprimentos principal apresenta condições adequadas para a produção de biscoito, porém a cadeia secundária apresenta limitação em relação à atuação dos gestores públicos, quanto a infraestrutura, treinamento e capacitação e as elevadas taxas e impostos. Considera-se que a atuação dos órgãos governamentais é incipiente no desenvolvimento do APL. De maneira geral, a gestão das empresas no APL é feita de forma incipiente sem o emprego de ferramentas e técnicas de gestão.

Na cadeia de suprimento do APL foi apresentado um grupo de vantagens, como acesso facilitado a fornecedores de matérias-primas, o acesso à mão de obra, a facilidade de distribuição da produção de forma direta ou por intermediários. Essas vantagens podem ser consideradas como importantes ativos do APL, podendo ser mais bem explorados com a melhoria na gestão das empresas, atuação mais efetiva dos órgãos públicos e melhor organização do APL.

As relações entre as empresas do aglomerado são caracterizadas pela competição. $\mathrm{Na}$ literatura são discutidos os benefícios da cooperação entre as empresas, no entanto, não foi possível evidenciar esse relacionamento. Portanto, questiona-se por que as empresas do APL não cooperam? Um fator que pode ser apresentado é em relação a barreira de entrada de novos concorrentes (PORTER, 1999), pois os processos produtivos não são elaborados ou tecnológicos e o investimento inicial pode ser considerado relativamente baixo para montagem de uma fábrica de biscoitos. Por outro lado, a competição entre as empresas pode possibilitar menores custos de produção, aumento da produtividade maior qualidade, novos processos produtivos e estímulo à formação de novas empresas conforme salientado por Porter (1999) e Kwasnicka e Zaccarelli (2007).

Nessa conjuntura, as características do APL podem ser associadas aos quatro atributos de competitividade desenvolvido por Porter (1999), assim, a competição entre as empresas proporciona o desenvolvimento delas. Por outro lado, nesse contexto de competição, foi recorrente a posição das empresas formalizadas, ou seja, registradas perante as exigências legais, 
alegando desvantagens frente às empresas informais que não tem a carga tributária, o controle de qualidade e a fiscalização dos órgãos reguladores.

Pelas características apresentadas do APL e a tipologia desenvolvida por Mytelka e Farinelli (2005), a tipologia do APL de São Tiago é informal, pois apresenta baixa capacidade de gestão e de tecnologia, com poucas inovações. As relações entre as empresas são fracas, com comportamento oportunista, forte competição e não existe ação compartilhada de compra de matéria-prima e venda de produtos.

Apesar do APL ser caracterizado como informal, as empresas consideram que o reconhecimento como polo produtor é uma vantagem competitiva para atração de consumidores, conforme Kwasnicka e Zaccarelli (2007) em função proximidade geográfica. Assim, destaca-se a relevância do município na geração de emprego, renda e desenvolvimento da região.

O estudo que foi realizado por Resende et al., (2012) o foco era no sistema de medição e desempenho das fábricas de biscoito, no entanto, algumas das suas indagações são compatíveis com as apresentadas nesse estudo. Os resultados da pesquisa de 2012 são semelhantes aos resultados nessa pesquisa, o que denotada que nesse período, considerando essas questões o APL não apresentou evolução.

A contribuição à academia foi a discussão a respeito da competição entre as empresas APL como um diferencial para competir com outras empresas fora do APL. Para o APL a contribuição é que os resultados possam ser utilizados pelas empresas e órgão públicos para possibilitar uma melhor gestão das empresas e desenvolvimento do APL.

A principal limitação da pesquisa refere-se ao survey ter sido realizada apenas no APL do município de São Tiago, o que não permite generalizações para outros arranjos produtivos. Além disso, não foi possível comparar essa pesquisa com outros estudos do mesmo seguimento devido à ausência de estudos. Sugerem-se futuras pesquisas em APL's que fazem pouco uso de tecnologia para verificar se o processo de competição pode estar associado à barreira de entrada de novos produtores ou se a competição entre as empresas é uma vantagem competitiva do APL.

Sugere-se as empresas do APL, avaliar a possibilidade do desenvolvimento de um relacionamento de interação e cooperação como forma de adquirir benefícios desses relacionamentos e o uso da competição. Assim, as empresas poderiam valer-se dos benefícios da cooperação e competição para maior desenvolvimento do APL, o que pode proporcionar um desempenho competitivo maior do que atuando de forma isolado no APL. Recomenda-se ainda 
a adoção de ferramentas e técnicas de gestão nas empresas. Aos órgãos governamentais sugerese uma maior inserção das instituições de apoio, como associações, Sebrae, Serviço Nacional de Aprendizagem Industrial (Senai), dentre outras.

Agradecimentos: Ao IF Sudeste MG pelo suporte financeiro.

\section{Referências}

AMARAL, MARCOS EDUARDO MONTEIRO. Vantagem Competitiva de empresas localizadas em Arranjos Produtivos Locais: um estudo teórico. In: Congresso Nacional de Excelência em Gestão. p. 1-21, 2013.

BALESTRIN, Alsones; VERSCHOORE, Jorge Renato; REYES JUNIOR, Edgar. O campo de estudo sobre redes de cooperação interorganizacional no Brasil. Revista de Administração Contemporânea, v. 14, n. 3, p. 458-477, 2010.

BARNEY, Jay B.; HESTERLY, William. Economia das organizações: entendendo a relação entre as organizações e a análise econômica. HANDBOOK de estudos organizacionais. São Paulo: Atlas, v. 3, p. 131-179, 2004.

BRASIL. Ministério do Desenvolvimento, Indústria e Comércio Exterior. Secretaria do Desenvolvimento da Produção. Departamento de Micro, Pequenas e Médias Empresas. Departamento de Competitividade e Tecnologia. Manual de Atuação em Arranjos Produtivos Locais, 2011.

BRITTO, Jorge. Cooperação interindustrial e redes de empresas. In: KUPFER, D.; HASENCLEVER, L. (Org.). Economia industrial: fundamentos teóricos e práticas no Brasil. Rio de Janeiro: Campus, p.345-388, 2002.

CHOPRA, Sunil; MEINDL, Peter. Gerenciamento da Cadeia de Suprimentos: Estratégia, Planejamento e Operação. In: Gerenciamento da Cadeia de Suprimentos: Estratégia, Planejamento e Operação. 2003.

COLLIS, J.; HUSSEY, R. Pesquisa em administração: um guia prático para alunos de graduação e pós-graduação. 2. ed. Porto Alegre: Bookman, 2005.

CORRÊA, Dalila Alves; GASTALDON, Osvaldo. Análise da competitividade de arranjos produtivos locais por meio do modelo diamante: uma revisão teórica. Revista de Ciência \& Tecnologia, v. 16, n. 32, p. 85-100, 2009.

CZERNEK, Katarzyna; CZAKON, W. Trust-building processes in tourist coopetition: The case of a Polish region. Tourism Management, v. 52, p. 380-394, 2016.

FLORIAN, Fabiana; LORENZO, Helena Carvalho de. Território e ambiente institucional: o arranjo produtivo local (APL) "Bordados de Ibitinga-SP". Revista Brasileira de Gestão e Desenvolvimento Regional, v. 4, n. 4, p. 25-53, 2008.

FURTADO, C. Raízes do subdesenvolvimento. Rio de Janeiro: Civilização Brasileira, 2003.

HAIR, Joseph F. et al. Análise multivariada de dados. Bookman Editora, 2009. 
HANSEN, Peter Bent; OLIVEIRA, Leonardo Rocha de. Proposta de Modelo para Avaliação Sistêmica do Desempenho Competitivo de Arranjos Produtivos-O Caso do Arranjo CoureiroCalçadista do Vale dos Sinos (RS-Brasil). Produto \& Produção, v. 10, n. 3, p. 61-75, 2009.

IBGE. Instituto Brasileiro de Geografia e Estatística. IBGE Cidades. Disponível em: <https://cidades.ibge.gov.br/brasil/mg/sao-tiago/panorama> Acesso: 15/01/2020.

IPIRANGA, Ana Sílvia Rocha; AMORIM, Mônica Alves; FARIA, Maria Vilma Coelho Moreira. Tecnologia social de mobilização para arranjos produtivos locais: uma proposta de aplicabilidade. Cadernos Ebape.BR, v. 5, n. 3, p. 1-23, 2007.

JUSTEN, Gelciomar S.; SOUZA, Mariluce P. de. Estruturas de governança no arranjo produtivo local (APL) da castanha-da-amazônia no estado do Acre. Revista Brasileira de Gestão e Desenvolvimento Regional, v. 13, n. 3, p. 252-275, 2017.

KWASNICKA, Eunice Lacava; ZACCARELLI, Sérgio Baptista. A Competitividade e Racionalidade de um Cluster Industrial. Revista de Administração da UNIMEP, v. 4, n. 2, p. 1-17, 2006.

LACOSTE, Sylvie. "Vertical coopetition": The key account perspective. Industrial Marketing Management, v. 41, n. 4, p. 649-658, 2012.

LEITE, Caio César Lemes et al. A LOGÍSTICA E A GESTÃO DA CADEIA DE SUPRIMENTOS: um estudo de caso em uma empresa da região do sul de Minas Gerais. Revista da Universidade Vale do Rio Verde, v. 15, n. 1, p. 676-688, 2017.

LUCCA, Emerson Juliano; TRENNEPOHL, Dilson. Perspectivas de mercado para as empresas do APL Pós-Colheita Panambi e Condor na ampliação da capacidade de armazenagem. COLÓQUIO - Revista do Desenvolvimento Regional, v. 13, n. 2, p. 65-83, 2016.

MACADAR, Beky Moron de. A inserção do Arranjo Produtivo Local (APL) moveleiro de Bento Gonçalves na cadeia produtiva de madeira e móveis. Ensaios FEE, v. 28, n. 2, 2007.

MACHADO, Santana; COSTA, Francisco Mendes; PÓLVORA, Alana Brito. Arranjo produtivo na produção do chocolate no município de Ilhéus: análise swot relacionada ao desenvolvimento local. Caribeña de Ciencias Sociales, n. noviembre, 2018.

MAGNAVITA, Waldemar. M. M.; BORIN, Elaine. C. P.; TERRA, Mariza. A. B. A mídia no desenvolvimento dos Arranjos Produtivos Locais: APL de moda praia de Cabo Frio. Revista Espacios, vol 32, no 3, 2011.

MARINI, Marcos Junior; SILVA, Christian Luiz da. A mensuração do potencial interno de desenvolvimento de um Arranjo Produtivo Local: uma proposta de aplicação prática. URBE. Revista Brasileira de Gestão Urbana, v. 6, n. 2, p. 236-248, 2014.

MARÔCO, João Paulo. Análise Estatística - Com Utilização do SPSS. 2a impr. Lisboa: Edições Silabo Lda, 2010.

MASQUIETTO, Clayton Daniel; SACOMANO NETO, Mário; GIULIANI, Antônio Carlos. Identificação de arranjos produtivos locais: o caso do arranjo produtivo local do álcool de Piracicaba. Gestão \& Regionalidade, v. 26, n. 77, p. 75-87, 2010.

MENDONÇA, Fabrício Molica et al. Condicionantes territoriais para formação, desenvolvimento e estruturação de arranjos produtivos locais: Um estudo comparativo em APLs de confecção do Estado de Minas Gerais. RAI Revista de Administração e Inovação, v. 9, n. 3, p. 231-256, 2012.

MTE. Ministério do Trabalho e Emprego. RAIS/CAGED: Perfil municipal. Disponível em: <http://bi.mte.gov.br/bgcaged/caged_perfil_municipio/index.php> Acesso em: 15/01/2020. 
MYTELKA, Lynn.; FARINELLI, Fulvia. De aglomerados locais a sistemas de inovação. In: LASTRES, H.M.M.; CASSIOLATO, J.E.; ARROIO, A. (Org.) Conhecimento, sistemas de inovação e desenvolvimento. Rio de Janeiro. UFRJ/Contraponto, 2005.

NALEBUFF, B.; BRANDENBURGER, A.; MAULANA, A. Co-opetition. London: HarperCollinsBusiness. 1996.

OLIVEIRA, Gilson. B. de. Uma discussão sobre o conceito de desenvolvimento. Revista da FAE, Curitiba, v. 5, n. 2, p. 37-48, 2002.

PESÄMAA, Ossi; HAIR JR, Joseph F. Cooperative strategies for improving the tourism industry in remote geographic regions: An addition to trust and commitment theory with one key mediating construct. Scandinavian Journal of Hospitality and Tourism, v. 8, n. 1, p. 48-61, 2008.

PORTER, M. A vantagem competitiva das nações. In: PORTER, M. Competição: estratégias competitivas essenciais. Rio de Janeiro: Campus, p. 167-208, 1999.

PORTER, M. Como as forças competitivas moldam a estratégia. In: MONTGOMERY, C. A.; PORTER, M. Estratégia: a busca da vantagem competitiva. Rio de Janeiro: Campus, p.11-27, 1998. p.

PRIETO, Evandro; LAURINDO, Fernando José Barbin; DE CARVALHO, Marly Monteiro. Alinhamento entre a estratégia do negócio e a gestão do relacionamento com o cliente: caso de uma empresa de telefonia. Revista Produção Online, v. 7, n. 2, p. 30-42, 2007.

Project Management Institute, editor. Um guia do conhecimento em Gerenciamento de Projetos (Guia PMBOK). Project Management Institute, 2017.

RESENDE, Paula C; SOARES, Suelem C; DIAS, Gabriella M; SILVA, Gustavo M. Proposição de um sistema de medição de desempenho para fábricas de biscoitos tradicionais em São Tiago (MG). Anais. XXXII Encontro Nacional de Engenharia de Produção. Bento Gonçalves, 2012.

RODRIGUEZ, Thais Helena P. T. Troca de conhecimento e ações conjuntas em um arranjo produtivo local ( $A P L$ ) de eventos da região do $A B C$. Dissertação (Mestrado em Administração) Universidade Municipal de São Caetano do Sul. São Caetano do Sul. 2014.

PREFEITURA MUNICIPAL DE SÃO TIAGO. São Tiago conquista certificado de Arranjo Produtivo Local. 2018. Disponível em: <http://saotiago.mg.gov.br/noticia/12188\#inicio_noticia> Acesso em $12 / 10 / 2018$.

SAMPAIO, Gustavo Cristiano; MARINI, Marcos Junior; SANTOS, Gilson Ditzel. Capital Social e Ações Conjuntas: um estudo de caso no Arranjo Produtivo de vinhos de altitude catarinense. Revista de Economia e Sociologia Rural, v. 56, n. 4, p. 605-622, 2018.

SANTOS, Luciano. D. Concorrência e cooperação em arranjos produtivos locais: o caso do polo de informática de Ilhéus/BA. Dissertação (Mestrado em Economia) - Universidade Federal da Bahia, Salvador, 2005.

SCHMITZ, Hubert; NADVI, Khalid. Industrial clusters in developing countries-clustering and industrialization: Introduction. World Development, v. 27, n. 9, p. 1503-1514, 1999.

SEBRAE. Serviço Brasileiro de apoio à Micro e Pequena Empresa. Termo de referência para atuação do SEBRAE em APLs. Brasília, 2003.

TAKEDA, Yoshiyuki et al. An analysis of geographical agglomeration and modularized industrial networks in a regional cluster: A case study at Yamagata prefecture in Japan. Technovation, v. 28, n. 8, p. 531-539, 2008. 
VIEIRA, Ariana Martins. Proposta de diretrizes para desenvolvimento coletivo de melhoria contínua em micro, pequenas e médias empresas de arranjos produtivos locais. 2011.

VIEIRA, Paulo Gonçalves Lins et al. Barreira à entrada regulatória e o cooperativismo de crédito no Brasil. 2016. 